\title{
The role of competitive intelligence on improving exports
}

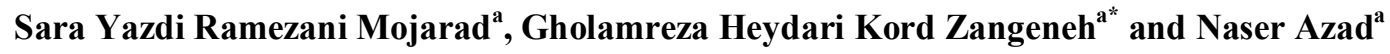

${ }^{a}$ Department of Management, Tehran South Branch, Islamic Azad University, Tehran, Iran

\section{H R O N I C L E}

Article history:

Received January 20, 2014

Accepted 30 August 2014

Available online

September 152014

Competitive Intelligence

Improved Exports

Decision Making

Competitiveness

\section{A B S T R A C T}

Competitive intelligence is the art of gathering, processing and analyzing the information about the competitors and environment in order to create and sustain the competitive advantage. The application of competitive intelligence in export companies can provide a complete picture of current and future competitive status for managers in addition to obtaining the most appropriate strategic decisions, which could ultimately lead to the improved exports in these companies. This study investigates the role of competitive intelligence for improvement of exports in Iranian industries. Using structural equation modeling, the study has detected six factors including understanding the competitive environment, intelligent response, superior features, customer orientation, managerial skills and competitive advantage.

\section{Introduction}

Economic globalization, accelerated technological changes, and the information explosion have placed higher pressure on the organizations to remain in the competitive world. Gathering and evaluating the information on the competing firms play the critical roles in developing the strategies. When a company is able to obtain information about the competing firms, it will be more likely to develop and implement the effective and successful strategies (David, 2010). Therefore, detecting, understanding and responding to the competitors have been considered as the particular aspects of marketing activities (Wright et al., 2002). The competitive intelligence is considered as a tool for strategic management and one the fastest growing causes of business growth around the world. The competitive intelligence, which is essential to a codified system, underlies the strategic decisions with an emphasis on the targeted gathering of competitive information (White, 1998). Receiving the information from the external environment of business influences on the firm's competitive position (Fuld \& Weylman, 1994), while about 90 percent of information a company needs for critical decisions can be obtained from the competitive intelligence (McGonagle \& Vella, 1999).

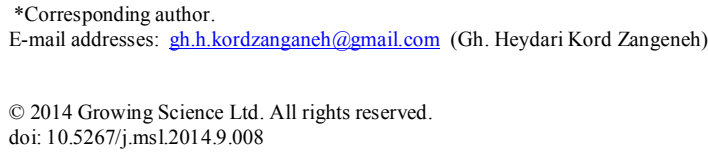


Strategic and Competitive Intelligence Professionals (SCIP) defines the competitive intelligence as follows: It is a systematic and ethical process for collecting, and managing the external information and influences the firms' plans, decisions and operation. In recent years, the economic globalization, accelerated technological changes, and the information explosion have put higher pressure on the firms to stay in the competitive world. On the other hand, by incorporating a variety of methods to collect the superiority, the information and communication technology (ICT) change the organizations to overcome the competitors. In today world, reaching the competitive is one of the undisputed necessities for most of the firms to be able to improve their abilities through acquisition and analysis of information as well as increasing the knowledge and creating the necessary awareness to make appropriate decisions. According to cases above, the utilization of competitive intelligence appears necessary for organizational success particularly in the field of sales and exports which are directly correlated with the competitors' behavior and changes in the surrounding environment.

\section{Research Literature}

\subsection{Competitive intelligence, objectives and advantages}

The objective and mission of competitive intelligence is to better preparation of users to be informed of the opportunities and threats in the external environment. The competitive intelligence can assist the firm in different ways such as providing the intelligent estimations, evaluation, information and insights about markets, the measures by competitors and the company itself (Dishman \& Calof, 2008; Tanev et al., 2008). The competitive intelligence plays essential role in the firm's strategy to sustain the competitive advantage and to help firms maintain the competitive advantage through the analysis and understanding of external environment of company. Furthermore, it helps the high-level management to make more informed decisions on the forthcoming events especially when the intelligence is systematically developed within a formal framework. To establish a market advantage, the firms should monitor a wide array of factors associated with the competitor's actions including all characteristics of business. In such an environment, the competitive intelligence has become a valuable tool for providing a framework for gathering, analyzing and disseminating this effort. More specifically, in demand economic repetition, an appropriate competitive intelligence can create some differentiation in the market. In the first step, the competitive intelligence is primarily established according to data collection using various marketing techniques and tools of company to scan a firm's external environment. Wright et al. (2002) defined the competitive intelligence as "a process of gathering the information by organizations about the competitors and competitive environment and using this ideal in decision-making and planning their processes with the aim at regulate the activities to improve the performance" (Gatsoris, 2012). Many studies indicate that the traditional forms of competitive intelligence based on the assessment of "competitors' objectives, financial results, successes and failures" are as well as competitors' assumptions about themselves and industry. The competitive intelligence, as a business tool, significantly leads to the strategic management process in modern business organizations and improves the business function by increasing the awareness, domestic relations, and quality of strategic plans (Sørensen, 2009). The competitive intelligence objectives include the management and risk mitigation, usefulness of information, preventing the information overload, ensuring the privacy and information security, and strategic use of corporate information. Wright et al. (2002) reported that the overall objective of competitive intelligence is to identify and act based on the signals, events and certain patterns which can improve the decisionmaking process of company. The competitive intelligence is normally classified into two ways; first, the strategic competitive intelligence, which can inform the senior management of threats and opportunities, while the latter, the tactical competitive intelligence which can be utilized for organizing the employees with the aim to make the required changes based on the insights obtained by the competitive intelligence. The whole information enables the companies to get a useful profile of their competitors (Gatsoris, 2012). 
The purpose of competitive intelligence is to contribute to the competitiveness of a firm while reducing the competitive advantage of its competitors. The competitive intelligence also provides the information about the competition while protecting the confidential information of firm from outsiders. The successful use of competitive intelligence helps a business be knowledgeable and aware of what is happening in its environment. It is believed that the competitive intelligence is necessary to make essential changes in an industry. The set of "market research" and "competitive intelligence" is called the market intelligence, which provides the practical analysis of business. The competitive intelligence is a critical source of information for business planning and other activities since it can provide the useful information about the competitors' present and future behavior and in general the business environment. Competitive intelligence is one of the most critical business principles. As a necessary function, the competitive intelligence is a key for performance of each business service. The competitive intelligence is so critical that it could separate the difference between the success and failure of an enterprise. The advantages of obtaining the competitive intelligence for business are far bigger than the expenses. There are four major advantages in this regard including Differentiation; Integrated Marketing Communication Plans; Pre-Selling an Idea to the Target Audience and Building Credibility with Your Customer.

During the diseconomy, the superior competitive intelligence can be the cause of differentiation in the market. When a company is able to evaluate the competition accurately by collecting the competitive information, this company is in a better position to make a difference for itself. A company may offer the lower cost in a competitive set, while another company have the superior process for providing the service. A company can utilize this information for a detailed assessment of questions like what the competition offers and how a company can separate itself from the competition (Johns \& Van Doren, 2010). The competitive intelligence is not limited to collect the information (Fleisher et al., 2003). The analysis of collected results indicates that there was a clear relationship between the competitive intelligence information applied by firms and their innovation performance. The specialized supplier firms are the most efficient users of competitive intelligence information. The information about the industry and competitors maintains the lowest rate of use, but strongly associated with the innovation performance of companies; and the information about the customers is also largely used in all firms and dramatically associated with the innovation. The practical intelligence information enables the executive management teams to make better strategic decisions and to take necessary actions in line with increasing the competitiveness and enhancing the innovative performance of company (Tanev \& Bailetti, 2008). The concept of intelligence is a longterm process proposed as an attempt to improve the firm's competitiveness and its strategic planning process. In fact, the definite competitive intelligence process includes five final stages of planning, focus, gathering, analysis, and communication, but this process is affected by a contextual effect - the organizational culture/ knowledge - and should be taken into account (Saayman et al., 2008).

\subsection{Utilization of competitive intelligence}

According to Pellissier and Kruger (2011), the following helps us understand the competitiveintelligence based activities in insurance organizations:

- Most companies increase the Accuracy and Reliability of their own information sources.

- Large corporations analyze their competitors and have the updated image of competitors, while the small organizations usually do not.

- Most companies adapt themselves to new technologies and have a full knowledge of advanced technologies in their fields.

- Most companies are aware of new and setting rules and procedures, which influence their firms.

- Analysis of competitors' products, websites, annual reports, and research reports are the most important sources for collecting competitive intelligence information. 
- The most common analytical techniques, implemented by firms to create the competitive intelligence, are the SWOT and competitors analyses both at a rate of 82 percent, and then the customer segmentation analysis with 72 percent, and industry analysis with 64\%, and finally the financial analysis and evaluation with a rate of $59 \%$.

- A few firms have managed to create a timely competitive intelligence and its transfer to management, while the larger firms have had more success in this regard. The large firms have a formal function of competitive intelligence, while the smaller firms generally have no formal and pre-designed competitive intelligence function.

However, the results state that a large number of firms utilize the competitive intelligence in making decisions (Pellissier \& Kruger, 2011). Furthermore, as the intelligence is systematically developed within a formal framework, it helps the top managers make informed and better decisions about future events. In most firms, the competitive intelligence is considered as an environmental scanning system, which integrates all members' knowledge in the organization and includes marketing, and structural, strategic and organizational elements. In a study on the British business (Wright et al., 2002), it was observed that the senior management had considered the competitive intelligence activities as the "proper application for company's status", "an important and integral part of company's success", and as "a long-term investment in increasing importance". According the cases above and the literature review in the field of competitive intelligence, 52 variables were identified and then dropped to 25 variables after refining by experts. The effective competitive intelligence variables are as follows:

\section{Table 1}

List of discovered variables after refinement

\begin{tabular}{llll}
\hline No. & Name of discovered variables & No. & Name of discovered variables \\
\hline 1 & Competitiveness & 14 & Pre-Selling an idea to the target audience \\
2 & Informed decisions (based on data) & 15 & Building Credibility With Your Customer \\
3 & Innovation & 16 & Sustaining the Competitive Advantage \\
4 & Gathering External Information & 17 & Create a market advantage \\
5 & Understanding The Company's External Environment & 18 & Scan the Company's External Environment \\
6 & Analyzing The Company's External Environment & 19 & Strategic Management \\
7 & Communication & 20 & Risk Management \\
8 & Emerging Technologies & 21 & Differentiation \\
9 & Informing of the Possible Opportunities & 22 & Market Research \\
10 & Informing of the Possible Threats & 23 & Awareness About Environment \\
11 & Competitors' action & 24 & Knowledge \\
12 & Analyze the Competitor & 25 & Accuracy of Information sources \\
13 & Marketing Communication Plans & & \\
\hline
\end{tabular}

\section{Research Methodology}

This study is applied in terms of objective, and descriptive according to the questions and among the causal techniques according to the research methods and generally a descriptive-survey study. In the first phase of research, the key concepts and variables were extracted by the review of literature in the field of competitive intelligence. The key extracted concepts were investigated through the literature review, interviews and consultation with experts; the similar cases were combined and repeated cases excluded. Thus, the sketch of questionnaire was prepared from explored variables. The advisor and supervisor professors and experts' viewpoints on this field were utilized for measuring the reliability of questionnaire, so that the sketch of questionnaire was examined by 10 experts who had the knowledge and experience as well as the willingness to cooperate in this field. Because of this investigation, a total of 25 variables from 52 discovered variables were detected reliable. The list of "key variables of competitive intelligence concept" is presented in Table 1. In the next step, a questionnaire containing 25 questions was designed and developed using these 25 variables. The theoretical principles of research questions and library studies were applied in developing the items of questionnaire. This questionnaire was designed with the options of completely disagree to completely 
agree and based on five-point Likert scale and distributed among the studied units after determining its validity and reliability.

The research population covers the Iranian petrochemical industry and the personnel's viewpoints in petrochemical companies and other informed and experts' views in the petrochemical industry were utilized in this study and the questionnaire was distributed among them. In the field of sample size, it should be noted that the sample size can be determined from 5 to 15 observations per each measure variable in structural equation modeling methodology $Q 15<N<Q 5$ where, $Q$ is the number of observed variables or items (questions) of questionnaire and $\mathrm{N}$ is the sample size. Therefore, due to the utilization of heuristic analytical technique in this study, the sample size was considered large $(\mathrm{N}=200)$ and the questionnaire was randomly distributed among 200 employees of the petrochemical industry as well as the experts in this regard and this number is acceptable according to the number of research variables $(\mathrm{N}=25)$ in the first questionnaire and the range of $\mathrm{Q} 15<\mathrm{N}<\mathrm{Q} 5$. After distributing and gathering the questionnaires and investigating the obtained responses, the data of questionnaire was analyzed using SPSS software version 21. In this study, the primary questionnaire was distributed among the statistical sample $(\mathrm{N}=200)$ and then Cronbach's alpha coefficient was calculated equal to 0.889 according to SPSS Software; it indicates the acceptable reliability of questionnaire. (Table 2).

\section{Table 2}

The results of reliability statistics

Cronbach's Alpha Cronbach's Alpha Based on Standardized Items $\quad \mathrm{N}$ of Items

$\begin{array}{lll}.889 & 889 & 25\end{array}$

According to one of the most important hypothesis of linear regression classic model, the error terms have the homoscedasticity. Among numerous methods for discovering the heteroscedasticity, Bartlett's Test of Sphericity is applied in this research to evaluate the significance of data in the correlation matrix and the Chi square of 1909.358 at the significance level of $\mathrm{P}<0.001$ indicates the detectable relationships between the variables in factor analysis. The results of this test are presented in Table 3. In the primary factor analysis, since Kaiser-Meyer-Olkin Measure of Sampling Adequacy (KMO) is equal to 0.780 (over $50 \%$ ), this questionnaire has the ability to be a factor with an acceptable value; furthermore, according to Bartlett's Test of Sphericity and because its value (sig $=0.000$ ) is less than $5 \%$ in the following table, the ability to be a factor is approved here (Table 3 ).

Table 3

KMO and Bartlett's Test

\begin{tabular}{lll}
\hline \multicolumn{2}{l}{ Kaiser-Meyer-Olkin Measure of Sampling Adequacy } & 0.78 \\
\hline \multirow{3}{*}{ Bartlett's Test of Sphericity } & Approx. Chi-Square & 1909.4 \\
& df & 300 \\
& Sig. & 0.000 \\
\hline
\end{tabular}

To identify the variables, which explained the lower factor loadings and had low correlations, the exploratory factor analysis was utilized through the principal components analysis combined with the orthogonal varimax rotation. The construct validity of questionnaire was assessed by factor analysis; Table 4 represents the Matrix of Communalities, Table 5 the Component Matrix, Table 6 the Total Variance Explained and Table 7 represents the Rotated Component Matrix. First and before performing the factor analysis, the suitability of data was assessed for factor analysis. Then again, the explanatory factor analysis was conducted with the type of principal components analysis with varimax rotation. After doing the factor analysis, a 7-factor structure was considered as shown in Table 8. 
Table 4

The results of Communalities

\begin{tabular}{|c|c|c|c|c|c|c|c|c|}
\hline$Q$ & Initial & Extraction & $Q$ & Initial & Extraction & $Q$ & Initial & Extraction \\
\hline 1 & 1 & 0.726 & 10 & 1 & 0.624 & 19 & 1 & 0.708 \\
\hline 2 & 1 & 0.557 & 11 & 1 & 0.577 & 20 & 1 & 0.663 \\
\hline 3 & 1 & 0.538 & 12 & 1 & 0.558 & 21 & 1 & 0.705 \\
\hline 4 & 1 & 0.669 & 13 & 1 & 0.759 & 22 & 1 & 0.788 \\
\hline 5 & 1 & 0.675 & 14 & 1 & 0.707 & 23 & 1 & 0.643 \\
\hline 6 & 1 & 0.664 & 15 & 1 & 0.383 & 24 & 1 & 0.721 \\
\hline 7 & 1 & 0.44 & 16 & 1 & 0.706 & 25 & 1 & 0.653 \\
\hline 8 & 1 & 0.723 & 17 & 1 & 0.807 & & & \\
\hline 9 & 1 & 0.774 & 18 & 1 & 0.645 & & & \\
\hline
\end{tabular}

Table 5

Component Matrix ${ }^{\mathrm{a}}$

\begin{tabular}{|c|c|c|c|c|c|c|c|}
\hline & \multicolumn{7}{|c|}{ Component } \\
\hline & 1 & 2 & 3 & 4 & 5 & 6 & 7 \\
\hline 18 & .698 & -.302 & & & & & \\
\hline 22 & .664 & & & & & -.363 & \\
\hline 10 & .626 & & & .303 & & & \\
\hline 17 & .598 & & -.363 & & .395 & & \\
\hline 16 & .596 & & & & .387 & & \\
\hline 19 & .585 & & & & & & .419 \\
\hline 21 & .575 & & & -.456 & & & \\
\hline 6 & .573 & -.545 & & & & & \\
\hline 12 & .569 & -.391 & & & & & \\
\hline 9 & .550 & & & .317 & -.438 & & \\
\hline 11 & .549 & & .314 & & & & \\
\hline 15 & .540 & & & & & & \\
\hline 23 & .537 & & .504 & & & & \\
\hline 4 & .529 & -.352 & .303 & & & & .308 \\
\hline 25 & .513 & & .327 & & & & \\
\hline 7 & .510 & .355 & & & & & \\
\hline 24 & .509 & & .404 & & .337 & & \\
\hline 20 & .503 & .306 & & -.374 & & & .358 \\
\hline 13 & .493 & & -.490 & & & .372 & \\
\hline 8 & & .577 & & & -.351 & .347 & \\
\hline 5 & .495 & -.559 & & & & & \\
\hline 3 & .443 & .450 & & & & & \\
\hline 14 & .415 & .371 & -.435 & & & & \\
\hline 2 & .394 & & & .580 & & & \\
\hline 1 & & .323 & & .328 & .390 & & .440 \\
\hline
\end{tabular}

Extraction Method: Principal Component Analysis.

a. 7 components extracted.

\section{Table 6}

Total Variance Explained

\begin{tabular}{|c|c|c|c|c|c|c|c|c|c|}
\hline \multirow[b]{2}{*}{ Component } & \multirow[b]{2}{*}{ Total } & \multirow{2}{*}{$\begin{array}{l}\text { Initial Eigenvalues } \\
\% \text { of Variance }\end{array}$} & \multirow[b]{2}{*}{ Cumulative } & \multicolumn{3}{|c|}{ Extraction Sums of Squared Loadings } & \multicolumn{3}{|c|}{ Rotation Sums of Squared } \\
\hline & & & & Total & $\%$ of & Cumulative & Total & $\%$ of & Cumulative \\
\hline 1 & 7.023 & 28.092 & 28.092 & 7.023 & 28.092 & 28.092 & 3.645 & 14.578 & 14.578 \\
\hline 2 & 2.415 & 9.660 & 37.752 & 2.415 & 9.660 & 37.752 & 2.414 & 9.657 & 24.235 \\
\hline 3 & 1.664 & 6.656 & 44.408 & 1.664 & 6.656 & 44.408 & 2.328 & 9.311 & 33.547 \\
\hline 4 & 1.491 & 5.962 & 50.370 & 1.491 & 5.962 & 50.370 & 2.227 & 8.907 & 42.454 \\
\hline 5 & 1.428 & 5.710 & 56.080 & 1.428 & 5.710 & 56.080 & 2.125 & 8.498 & 50.952 \\
\hline 6 & 1.285 & 5.140 & 61.220 & 1.285 & 5.140 & 61.220 & 2.089 & 8.357 & 59.309 \\
\hline 7 & 1.107 & 4.427 & 65.647 & 1.107 & 4.427 & 65.647 & 1.585 & 6.338 & 65.647 \\
\hline 8 & .934 & 3.737 & 69.384 & & & & & & \\
\hline 9 & .865 & 3.459 & 72.843 & & & & & & \\
\hline 10 & .802 & 3.208 & 76.051 & & & & & & \\
\hline 11 & .736 & 2.946 & 78.997 & & & & & & \\
\hline 12 & .669 & 2.678 & 81.675 & & & & & & \\
\hline 13 & .561 & 2.243 & 83.917 & & & & & & \\
\hline 14 & .551 & 2.205 & 86.123 & & & & & & \\
\hline 15 & .500 & 2.001 & 88.124 & & & & & & \\
\hline 16 & .445 & 1.779 & 89.903 & & & & & & \\
\hline 17 & .414 & 1.655 & 91.558 & & & & & & \\
\hline 18 & .399 & 1.595 & 93.153 & & & & & & \\
\hline 19 & .339 & 1.355 & 94.508 & & & & & & \\
\hline 20 & .323 & 1.292 & 95.800 & & & & & & \\
\hline 21 & .279 & 1.115 & 96.914 & & & & & & \\
\hline 22 & .223 & .893 & 97.808 & & & & & & \\
\hline 23 & .220 & .881 & 98.688 & & & & & & \\
\hline 24 & .185 & .741 & 99.430 & & & & & & \\
\hline 25 & .143 & .570 & 100.000 & & & & & & \\
\hline
\end{tabular}

Extraction Method: Principal Component Analysis. 
Table 7

Rotated Component Matrix ${ }^{\mathrm{a}}$

\begin{tabular}{|c|c|c|c|c|c|c|c|}
\hline & 1 & 2 & 3 & $\begin{array}{c}\text { Component } \\
4\end{array}$ & 5 & 6 & 7 \\
\hline 5 & .773 & & & & & & \\
\hline 4 & .687 & & .306 & & & & \\
\hline 12 & .673 & & & & & & \\
\hline 6 & .672 & & & .421 & & & \\
\hline 11 & .610 & .427 & & & & & \\
\hline 16 & .571 & & & & .363 & & .468 \\
\hline 18 & .557 & & & .478 & & & \\
\hline 24 & & .798 & & & & & \\
\hline 23 & & .674 & & & & & \\
\hline 25 & & .666 & & & & & \\
\hline 19 & .301 & & .759 & & & & \\
\hline 20 & & & .724 & & & & \\
\hline 8 & & & .560 & -.428 & & .356 & \\
\hline 7 & & & .477 & & & .327 & \\
\hline 22 & & .467 & & .681 & & & \\
\hline 21 & & & .341 & .678 & & & \\
\hline 13 & & & & & .831 & & \\
\hline 14 & & & & & .803 & & \\
\hline 15 & & & & .340 & .366 & & \\
\hline 9 & & & & & & .809 & \\
\hline 2 & & & & & & .561 & .359 \\
\hline 10 & .436 & & & & & .544 & \\
\hline 3 & & .347 & .380 & & & .479 & \\
\hline 1 & & & & & & & .799 \\
\hline 17 & & & & .566 & .313 & & .580 \\
\hline
\end{tabular}

The results of factor analysis indicate that the questionnaire has appropriate construct validity. Finally, according to the consultation with experts participating in the study, six out of seven questionnaire factors were confirmed and named and the results are presented in Table 8. Based on the obtained results, six primary factors of competitive intelligence with the impact on the improved exports in this research are as follows: Understanding the competitive environment with 7 items, intelligent response with 5 items, superior features with four items, customer satisfaction, managerial skills and competitive advantage each which with 3 items and the order of their importance is presented in the confirmatory factor analysis section.

\section{Table 8}

List of components and their constituent variables

\begin{tabular}{|c|c|c|c|}
\hline Component & Name of component & Name of variable & Factor Weight \\
\hline \multirow{7}{*}{1} & \multirow{7}{*}{ Understanding the competitive environment } & Understanding The Company's External Environment & 0.773 \\
\hline & & Analyze the Competitor & 0.673 \\
\hline & & Gathering External Information & 0.687 \\
\hline & & Analyzing The Company's External Environment & 0.672 \\
\hline & & Scan the Company's External Environment & 0.557 \\
\hline & & Informing of the Possible Threats & 0.436 \\
\hline & & Strategic Management & 0.301 \\
\hline \multirow{5}{*}{2} & \multirow{5}{*}{ Intelligent Response } & Knowledge & 0.798 \\
\hline & & Awareness About Environment & 0.674 \\
\hline & & Accuracy of Information sources & 0.666 \\
\hline & & Market Research & 0.467 \\
\hline & & Competitors' action & 0.427 \\
\hline \multirow{4}{*}{3} & \multirow{4}{*}{ Superior Features } & Risk Management & 0.724 \\
\hline & & Emerging Technologies & 0.560 \\
\hline & & Communication & 0.477 \\
\hline & & Differentiation & 0.341 \\
\hline \multirow{4}{*}{4} & \multirow{4}{*}{ Customer orientation } & Marketing Communication Plans & 0.831 \\
\hline & & Pre-Selling an idea to the target audience & 0.803 \\
\hline & & Building Credibility With Your Customer & 0.366 \\
\hline & & Marketing Communication Plans & 0.831 \\
\hline \multirow{3}{*}{5} & \multirow{3}{*}{ Managerial skills } & Informing of the Possible Opportunities & 0.809 \\
\hline & & Informed decisions & 0.561 \\
\hline & & Innovation & 0.479 \\
\hline \multirow{3}{*}{6} & \multirow{3}{*}{ Competitive advantage } & Competitiveness & 0.799 \\
\hline & & Create a Market Advantage & 0.580 \\
\hline & & Sustaining Competitive Advantage & 0.468 \\
\hline
\end{tabular}


After achieving the effective factors of competitive intelligence, the structural model for the impact of these components on the improved exports was presented at the second stage. In this regard, a questionnaire was initially developed for assessing the impact of constitutive variables of these components on the improved export and the questionnaires were distributed among 200 samples of statistical population. According to data obtained from AMOS software, the structural modeling was accomplished and the results are shown in Fig. 1 as follows.

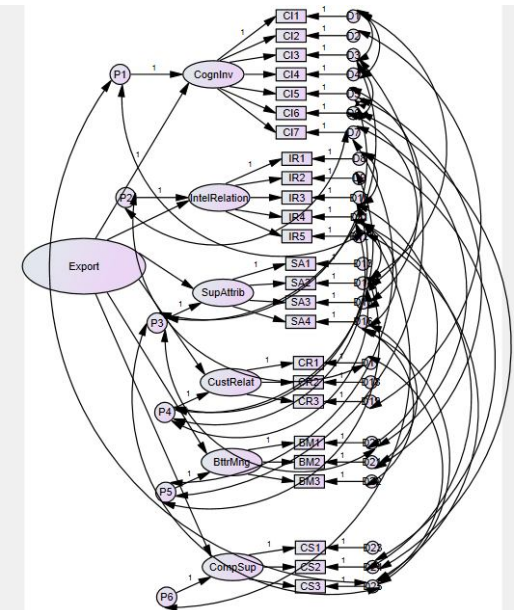

Standard structural model

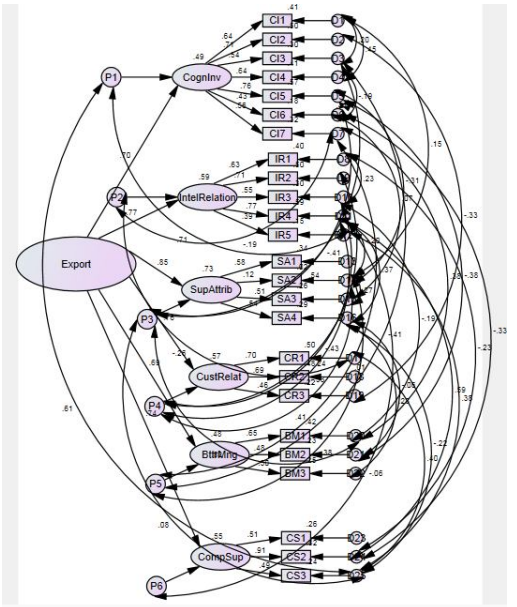

Revised structural model with standardized coefficients

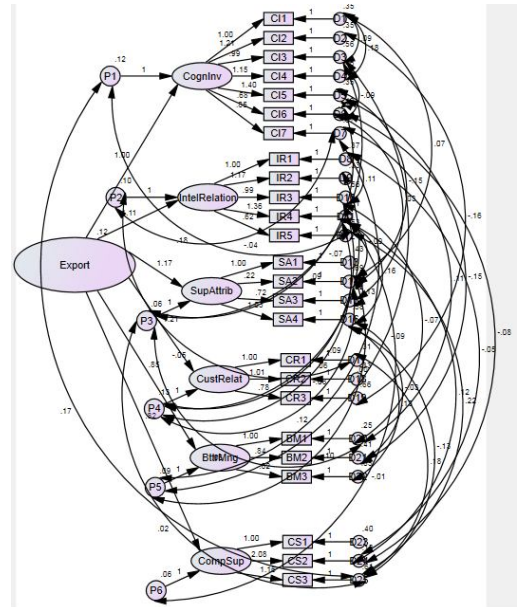

Revised structural model with nonstandardized coefficients

Fig. 1. Fitting 6 factor models for the impact of competitive intelligence on improves exports

Table 9

Ranking the Factors

\begin{tabular}{lll}
\hline Dependent variable & Exploratory components & Importance factor \\
\hline & Understand the competitive environment & 0.70 \\
& Intelligent response & 0.77 \\
& Superior features & 0.55 \\
Improved exports & Customer orientation & 0.76 \\
& Managerial skills & 0.69 \\
& Competitive advantage & 0.74 \\
\hline
\end{tabular}

Table 10

Explanatory factors and importance factor

\begin{tabular}{|c|c|c|c|}
\hline & Name of component & Name of Variable & Importance factor \\
\hline \multirow{7}{*}{1} & \multirow{7}{*}{ Understanding the competitive environment } & Understanding The Company's External Environment & 0.64 \\
\hline & & Analyze the Competitor & 0.71 \\
\hline & & Gathering External Information & 0.54 \\
\hline & & Analyzing The Company's External Environment & 0.64 \\
\hline & & Scan the Company's External Environment & 0.76 \\
\hline & & Informing of the Possible Threats & 0.56 \\
\hline & & Strategic Management & 0.43 \\
\hline \multirow{5}{*}{2} & \multirow{5}{*}{ Intelligent Response } & Knowledge & 0.63 \\
\hline & & Awareness About Environment & 0.71 \\
\hline & & Accuracy of Information sources & 0.55 \\
\hline & & Market Research & 0.77 \\
\hline & & Competitors' action & 0.39 \\
\hline \multirow{4}{*}{3} & \multirow{4}{*}{ Superior Features } & Risk Management & 0.58 \\
\hline & & Emerging Technologies & 0.12 \\
\hline & & Communication & 0.51 \\
\hline & & Differentiation & 0.54 \\
\hline \multirow{3}{*}{4} & \multirow{3}{*}{ Customer orientation } & Marketing Communication Plans & 0.70 \\
\hline & & Pre-Selling an idea to the target audience & 0.69 \\
\hline & & Building Credibility With Your Customer & 0.46 \\
\hline \multirow{3}{*}{5} & \multirow{3}{*}{ Managerial skills } & Informing of the Possible Opportunities & 0.65 \\
\hline & & Informed decisions & 0.48 \\
\hline & & Innovation & 0.50 \\
\hline \multirow{3}{*}{6} & \multirow{3}{*}{ Competitive advantage } & Competitiveness & 0.51 \\
\hline & & Create a market advantage & 0.91 \\
\hline & & Sustaining Competitive Advantage & 0.49 \\
\hline
\end{tabular}




\section{Discussion and Conclusion}

In today's world and according to various changes of globalization, only the organizations, which have the precise, updated and sufficient information about themselves, customers, competitors, and surrounding environment through the widespread marketing research, can survive in the competitive market. This information will be useful when properly analyzed based on the firm's strategic and short-term objectives in order to help the senior managers make the best, most accurate and efficient competitive decisions and strategies. What mentioned above is closely associated with the concept of competitive intelligence. In fact, the competitive intelligence is the art of gathering, storing and processing the information to keep up with the competitive advantage. Despite the fact that the competitive intelligence is among the new concepts of marketing management, all successful firms take advantage of the competitive intelligence in their decisions even if there is no formal function for competitive intelligence management. The importance of competitive intelligence issue becomes enhanced when an organization intends to enter in the global and export markets because the slightest wrong decisions and actions in the international markets can lead the company to the failure. Thus, the competitive intelligence can lead to making the accurate and timely decisions on the exports policies and ultimately the improvement and development of exports.

\section{First question: What are the competitive intelligence factors affecting the improved exports?}

As mentioned, from a total of 25 measured variables in the questionnaire of Eigenvalues, 7 variables are more than 1 and the percentage of common variance among the variables for these seven factors generally explains 65.647 Percent of the total variance of variables. In other words, the amount of expressed accuracy by these seven factors is totally more than 65 percent. It should be noted that, the fourth factor was removed while naming and the number of factors dropped to 6 .

Given the results of first question, 6 hypotheses can be provides as follows:

\section{First Hypothesis}

1- "Understanding the competitive environment" component has an impact on improved exports.

Based on the statistical analysis, the net correlation coefficient is significant with the base level of 0.70 for "Understanding the competitive environment" component in relation to the improved exports. In other words, any changes in the variance of infrastructure component lead to 0.70 changes in the variance of improved exports.

\section{Second hypothesis}

2- "Intelligent Response" component has an impact on improved exports.

Based on the statistical analysis, the net correlation coefficient is significant with the base level of 0.77 and $t=5.362$ for "Intelligent Response" component in relation to the improved exports. In other words, any changes in the variance of Intelligent Response component lead to 0.77 changes in the variance of improved exports.

\section{Third hypothesis}

3 - "Superior features" component has an impact on improved exports.

Based on the statistical analysis, the net correlation coefficient is significant with the base level of 0.85 and $t=5.451$ for "Superior features" component in relation to the improved exports. In other 
words, any changes in the variance of "Superior features" component lead to 0.85 changes in the variance of improved exports.

\section{Fourth hypothesis}

4- "Customer Orientation" component has an impact on improved exports.

Based on the statistical analysis, the net correlation coefficient is significant with the base level of 0.76 and $\mathrm{t}=5.343$ for "Customer Orientation" component in relation to the improved exports. In other words, any changes in the variance of "Customer Orientation" component lead to 0.76 changes in the variance of improved exports.

\section{Fifth hypothesis}

5- "Managerial skills" component has an impact on improved exports.

Based on the statistical analysis, the net correlation coefficient is significant with the base level of 0.69 and $t=5.038$ for "Managerial skills" component in relation to the improved exports. In other words, any changes in the variance of "Managerial skills" component lead to 0.69 changes in the variance of improved exports.

\section{Sixth hypothesis}

6 - "Competitive Advantage" component has an impact on improved exports.

Based on the statistical analysis, the net correlation coefficient is significant with the base level of 0.74 and $t=4.907$ for "Competitive Advantage" component in relation to the improved exports. In other words, any changes in the variance of "Competitive Advantage" component lead to 0.74 changes in the variance of improved exports.

The results of Table 11 indicate that all 10 hypotheses are accepted.

Second question: To what extent do the competitive intelligence critical components affect the improved exports?

Based on the obtained results, the "Superior Features" with 4 items, the "Intelligent Response" with 5 items, and "Customer Orientation" with 3 items are three primary factors of packaging the exporting goods affecting the increased exports based on the importance in this study. Given the cases above in the field of investigating the competitive intelligence factors affecting the improved exports, the "superior features" component (with the importance factor of 0.85), and "intelligent response" (with the importance factor of 0.77), and the customer orientation (with the importance factor of 0.76) are put at the next priorities respectively, and can be considered by managers and planners in the organization.

Based on the obtained results, the competitive advantage with 3 items, understanding the competitive environment with 7 items, and managerial skills with 3 items are three second factors of competitive intelligence affecting the improved exports.

According to the cases above, the importance of second three factors in the improved exports is as follows respectively: competitive advantage (with importance factor of 0.74 ), understanding the competitive environment (with importance factor of 0.70) and managerial skills (with importance 
factor of 0.69); despite the fact that according to the importance factor, there are no significant difference among these values. The summary of cases above is presented in Table 9.

Third question: What is the structural model for the impact of competitive intelligence components on improved export?

Based on the obtained results of confirmatory factor analysis and the output of Amos software, the importance of each variable on the components is described in Table 10. (Table 10 is designed based on the standard model):

Table 11

Rejection or acceptation Status of main hypotheses

\begin{tabular}{|c|c|c|c|c|}
\hline & Main hypotheses & $\mathrm{p}$ & $\begin{array}{l}\text { Estimate } \\
\beta\end{array}$ & $\begin{array}{l}\text { Acceptation/rejection of } \\
\text { hypothesis }\end{array}$ \\
\hline \multirow{6}{*}{$\begin{array}{l}\text { Impact of competitive } \\
\text { intelligence factors on } \\
\text { improved exports }\end{array}$} & $\begin{array}{l}\text { "Understanding the competitive environment" has an impact on } \\
\text { improved exports. }\end{array}$ & $\mathrm{P}<0.001$ & 1000 & Accepted \\
\hline & "Intelligent Response" has an impact on improved exports. & $\mathrm{P}<0.001$ & 1.105 & Accepted \\
\hline & "Superior features" has an impact on improved exports. & $\mathrm{P}<0.001$ & 1.173 & Accepted \\
\hline & "Customer orientation" has an impact on improved exports. & $\mathrm{P}<0.001$ & 1.209 & Accepted \\
\hline & "Managerial skills" has an impact on improved exports. & $\mathrm{P}<0.001$ & 0.848 & Accepted \\
\hline & "Competitive advantage" has an impact on improved exports. & $\mathrm{P}<0.001$ & 0.816 & Accepted \\
\hline
\end{tabular}

Table 12 also shows that all sub-hypotheses are accepted.

\section{Table 12}

Rejection or Acceptation Status of sub-hypotheses

\begin{tabular}{|c|c|c|c|c|}
\hline $\begin{array}{l}\text { Subsidiary Hypothesis } \\
\text { "The impact of the following variables on improving exports." }\end{array}$ & $\mathrm{P}$ & $\begin{array}{l}\text { Estimate } \\
\text { (Estimation of factor } \\
\text { coefficient) }\end{array}$ & $\begin{array}{l}\text { Rejection of } \\
\text { hypothesis }\end{array}$ & Acceptation of hypothesis \\
\hline Knowledge & $\mathrm{P}<0.001$ & 1.000 & & Accepted \\
\hline Awareness About Environment & $\mathrm{P}<0.001$ & 1.166 & & Accepted \\
\hline Accuracy of Information sources & $\mathrm{P}<0.001$ & 0.989 & & Accepted \\
\hline Market Research & $\mathrm{P}<0.001$ & 1.356 & & Accepted \\
\hline Competitors' action & $\mathrm{P}<0.001$ & 0.618 & & Accepted \\
\hline Understanding The Company's External Environment & $\mathrm{P}<0.001$ & 1.000 & & Accepted \\
\hline Analyze the Competitor & $\mathrm{P}<0.001$ & 1.206 & & Accepted \\
\hline Gathering External Information & $\mathrm{P}<0.001$ & 0.990 & & Accepted \\
\hline Analyzing The Company's External Environment & $\mathrm{P}<0.001$ & 1.154 & & Accepted \\
\hline Scan Company's External Environment & $\mathrm{P}<0.001$ & 1.400 & & Accepted \\
\hline Strategic Management & $\mathrm{P}<0.001$ & 0.679 & & Accepted \\
\hline Informing of the Possible Threats & $\mathrm{P}<0.001$ & 0.846 & & Accepted \\
\hline Risk Management & $\mathrm{P}<0.001$ & 1.000 & & Accepted \\
\hline Emerging Technologies & $\mathrm{P}<0.001$ & 0.218 & & Accepted \\
\hline Communication & $\mathrm{P}<0.001$ & 0.717 & & Accepted \\
\hline Differentiation & $\mathrm{P}<0.001$ & 1.029 & & Accepted \\
\hline Marketing Communication Plans & $\mathrm{P}<0.001$ & 1.000 & & Accepted \\
\hline Pre-Selling an idea to the target audience & $\mathrm{P}<0.001$ & 1.009 & & Accepted \\
\hline Building Credibility With Your Customer & $\mathrm{P}<0.001$ & 0.775 & & Accepted \\
\hline Informing of the Possible Opportunities & $\mathrm{P}<0.001$ & 1.000 & & Accepted \\
\hline Informed decisions & $\mathrm{P}<0.001$ & 0.835 & & Accepted \\
\hline Innovation & $\mathrm{P}<0.001$ & 0.817 & & Accepted \\
\hline Competitiveness & $\mathrm{P}<0.001$ & 1.000 & & Accepted \\
\hline Create a Market Advantage & $\mathrm{P}<0.001$ & 2.079 & & Accepted \\
\hline Sustaining Competitive Advantage & $\mathrm{P}<0.001$ & 1.164 & & Accepted \\
\hline
\end{tabular}

\section{Suggestions for future research}

This research is an exploratory study including the effective competitive intelligence components including "understanding the competitive environment, intelligent response, managerial skills, customer orientation, etc.". It seems that this study will be able to create the infrastructures for other researchers, thus the following cases subjects are recommended for future studies: 
- The role of competitive intelligence on enhanced sales

- The role of competitive intelligence on enhanced market share

- The role of competitive intelligence on enhanced export development.

\section{Acknowledgement}

The authors would like to thank the anonymous referees for constructive comments on earlier version of this paper.

\section{References}

Adidam, P. T., Banerjee, M., \& Shukla, P. (2012). Competitive intelligence and firm's performance in emerging markets: an exploratory study in India. Journal of Business \& Industrial Marketing, 27(3), 242-254.

David, F. R. (2010). Strategic Management : Concepts. $13^{\text {th }}$ ed.

Dishman, P. L., \& Calof, J. L. (2008). Competitive intelligence: a multiphasic precedent to marketing strategy. European Journal of Marketing, 42(7/8), 766-785.

Fleisher, C. S., Knip, V., \& Dishman, P. (2003). Chronological and categorized bibliography of key competitive intelligence scholarship: part 2 (1990-1996).Journal of Competitive Intelligence and Management, 1(2), 11-88.

Francis, J., \& Collins-Dodd, C. (2004). Impact of export promotion programs on firm competencies, strategies and performance: The case of Canadian high-technology SMEs. International Marketing Review, 21(4/5), 474-495.

Fuld, L. M., \& Weylman, C. R. (1994). The new competitor intelligence. Audio-Tech Business Book Summaries.

Gatsoris, L. (2012). Competitive intelligence in Greek furniture retailing: a qualitative approach. EuroMed Journal of Business, 7(3), 224-242.

Johns, P., \& Van Doren, D. C. (2010). Competitive intelligence in service marketing: A new approach with practical application. Marketing Intelligence \& Planning, 28(5), 551-570.

McGonagle, J. J., \& Vella, C. M. (1999). The Internet age of competitive intelligence. Greenwood Publishing Group.

Pellissier, R., \& Kruger, J. P. (2011). A study of strategic intelligence as a strategic management tool in the long-term insurance industry in South Africa.European Business Review, 23(6), 609-631.

Saayman, A., Pienaar, J., De Pelsmacker, P., Viviers, W., Cuyvers, L., Muller, M. L., \& Jegers, M. (2008, July). Competitive intelligence: construct exploration, validation and equivalence. In Aslib Proceedings (Vol. 60, No. 4, pp. 383-411). Emerald Group Publishing Limited.

Sørensen, H. E. (2009). Why competitors matter for market orientation.European Journal of Marketing, 43(5/6), 735-761.

Tanev, S., \& Bailetti, T. (2008). Competitive intelligence information and innovation in small Canadian firms. European Journal of Marketing, 42(7/8), 786-803.

White, D. (1998). Competitive intelligence. Work Study, 47(7), 248-250.

Wright, S., Pickton, D. W., \& Callow, J. (2002). Competitive intelligence in UK firms: a typology. Marketing Intelligence \& Planning, 20(6), 349-360. 